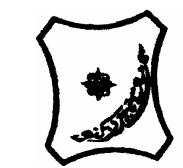

Bayero Journal of Pure and Applied Sciences, 3(1): 195 - 198

Received: May, 2010

Accepted: June, 2010

\title{
INHIBITORY ACTIVITY OF PSIDIUM GUAJAVA EXTRACTS ON SOME CONFIRMED EXTENDED-SPECTRUM B-LACTAMASES PRODUCING ESCHERICHIA COLI, KLEBSIELLA PNEUMONIAE AND PROTEUS VULGARIS ISOLATES
}

\author{
M. Yusha'u \\ Department of Biological Sciences, Bayero University, P. M. B. 3011, Kano \\ mryushau@gmail.com
}

\begin{abstract}
Psidium guajava (L.) leaves powder was extracted with ethanol and methanol using percolation method. The extracts were tested for antimicrobial activity against clinical isolates of confirmed extended spectrum $\beta$-lactamase producing Escherichia coli, Klebsiella pneumoniae and Proteus vulgaris isolates using disc diffusion method. The extracts were further subjected to phytochemical tests using standard procedures. Sensitivity test results showed that ethanol extract of the plant was active against $K$. pneumoniae and Proteus vulgaris $(8 \mathrm{~mm})$ but inactive against $E$. coli at $30 \mu \mathrm{g} /$ disc concentration while methanol extract of the plant was active against Proteus vulgaris isolates (8mm) but inactive against the remaining isolates at $30 \mu \mathrm{g} /$ disc concentration. Both extracts were active against ESBLs producing Proteus isolates with similar zone of inhibition in response to equal concentration of the extracts. The results of phytochemical screening indicated the presence of alkaloids, reducing sugars, saponins, steroids and tannins in either or both extracts.
\end{abstract}

Keywords: Sensitivity, ESBLs, Enterobacteriaceae, Psidium guajava, Extracts

\section{INTRODUCTION}

Medicinal plants are cheap and renewable source of pharmacologically active substances and are known to produce certain chemicals that are naturally toxic to bacteria (Basile et al., 1999). The use of herbal medicine is popular in several local communities in Nigeria as well as other developing countries. Prominent among the reasons is poverty among the populace as well as lack of basic primary health care system (Oke, 2000). Indeed generalized and highly exaggerated attributes have been associated with the potency of some of these plants against several ailments without any scientific and documented reports to backup some of the widely held claims. In any case plants provide about $80 \%$ of the remedies for several diseases and are cheap, readily available and safer alternative source of antibacterial agents (Sofowora, 1993).

Psidium guajava is a small tree about $33 \mathrm{ft}$ (10in) high with spreading branches found throughout the rain forest and in the tropical countries like Latin America, Central and West Africa, Pacific tropical regions, Amazon basic and South East Asia (www. tropical plant database). The stem bark of guava is smooth, thin, copper showing a greenish layer beneath the leaves aromatic when crushed are ever green opposite, short petiole oval or oblong - elliptic 7- $15 \mathrm{~cm}$ long and $3-5 \mathrm{~cm}$ wide with conspicuous our parallel veins and more or less downy on the underside. Faintly fragrant the white leaves are borne single or in small clusters in the leaf axils are $2-5 \mathrm{~cm}$ wide. The fruit exuding a strong sweet musky odor when ripe may be round ovoid or pear shaped, with light yellow skin frequently blushed with pink. The seed counts found in the fruit ranged from 112 to 535 but some are nearly seedless (Aliyu, 2006).

Biomedical studies on the use of Psidium guajava plant resource in the treatment of gastrointestinal ailments has shown that the used guava product decreased the duration of abdominal pain in the patients. Anti-cough activity of $P$. guajava leaf extract evaluated in rats and guinea pigs showed that water extract of the plant decreased the frequency of cough. Moreover growth of $S$. aureus and $\beta$-haemolytic Streptococcus group $A$ as determined by disc diffusion method was inhibited by water, methanol and chloroform extract of dry leaves (Jaiary et al., 1999).

Extended spectrum $\beta$-lactamases (ESBLs) are enzymes that confer variable level of resistance to oxyiminocephalosporins such as cephotaxime, ceftazidime and monobactams. They occur predorminantly in the family enterobacteriaceae with Klebsiella pneumoniae being the most commonly reported worldwide and it is responsible for $5-20 \%$ of outbreaks of nosocomial infections in intensive care units, burn, oncology and neonatal units (Kotra, et al, 2002). At present there exist more than 200 different natural variants worldwide which constitute serious threat to current $\beta$-lactam therapies and represent major therapeutic challenges for clinicians (Lin et al., 2005). 
Patients at risk of infection with ESBLs-producing organisms are seriously ill patients with prolonged hospital stays and those in whom invasive medical devices (such as catheters) are present for prolonged duration with the length of hospital stay prior to isolation of ESBL producer ranging from 11-67 days (Lautenbach et al., 2001). Other risk factors for infection include presence of nasogastric tubes (Asensio et al., 2000), recent surgery and poor nutritional status (Paterson and Bonomo, 2005), haemodialysis (D'Agata et al, 1998) as well as selective pressure on the use and overuse of antibiotics (Cosgrove et al., 2002). The objective of this research was to determine sensitivity of ESBLs producers to Psidium guajava extracts with the aim of finding alternative treatment(s) to infections caused by such organisms.

\section{MATERIALS AND METHODS}

\section{Collection of plant materials}

Psidium guajava leaves were collected from Biological sciences garden at Bayero University Kano, washed and air dried at room temperature. Dried leaves were ground into fine powder using mortar and pestle in the laboratory as described by Mukhtar and Tukur (1999).

\section{Extraction}

Fifty grams each of the powdered plant was soaked in $500 \mathrm{ml}$ of ethanol and methanol in separate conical flasks and kept for two weeks in a shaker after which the mixture was filtered. The filtrate was evaporated at room temperature (Fatope et al., 1993).

\section{Phytochemical screening}

\section{Test for alkaloids}

To $0.1 \mathrm{ml}$ of each extract in two separate test tubes 2 - 3 drops of Dragendoff's reagent were added. An orange red precipitate/turbidity indicates the presence of alkaloids (Ciulci, 1994).

\section{Test for flavonoids}

To $4 \mathrm{mg} / \mathrm{ml}$ of each of the fractions a piece of magnesium ribbon was added this was followed by concentrated $\mathrm{HCl}$ drop wise. A colour change ranging from orange to red indicated flavones while red to crimson indicated flavonoids (Sofowora, 1993)

\section{Test for glycosides}

Ten mls of $50 \% \mathrm{H}_{2} \mathrm{SO}_{4}$ was added to $1 \mathrm{~cm}^{3}$ of the filtrates in separate test tubes. The mixtures were heated for $15 \mathrm{mins} .10 \mathrm{~cm}^{3}$ of Fehling's solution was added and the mixture boiled. A brick red precipitate indicated presence of glycosides (Sofowora ,1993).

\section{Test for reducing sugars}

One $\mathrm{ml}$ of each fraction in separate test tubes was diluted with $2.0 \mathrm{ml}$ of distilled water followed by addition of Fehling's solution $(A+B)$ and warming. Appearance of brick red precipitate at the bottom of the test tube indicates presence of reducing sugar (Brain and Turner, 1976).

\section{Test for saponins}

Half gram of each of the extract was dispensed in a test tube each. $5.0 \mathrm{ml}$ of distilled water was added and shaken vigorously. A persistent froth that lasts for about 15 minutes would indicate the presence of saponins (Brain and Turner, 1975).

\section{Test for steroids}

Two mls of the dry extracts were taken into separate test tubes. The residues were dissolved in acetic anhydride and chloroform was then added. This was followed by the addition of concentrated sulphuric acid by the side of the test tubes using a pipette. A brown ring at the interface of the two liquids and a violet colour in the supernatant layer denoted the presence of steroids (Ciulci, 1994).

\section{Test for tannins}

Two mls of each of the extract was diluted with distilled water in separate test tube and $2-3$ drops of $5 \%$ ferric chloride $\left(\mathrm{FeCl}_{3}\right)$ solution was added. A green - black or blue colouration would indicate tannin (Ciulci, 1994).

\section{Disc preparation}

Improvised discs were punched from Whatman No. 1 filter paper, sterilized in bijou bottles by autoclaving at $121^{\circ} \mathrm{C}$ for 15 mins. Sensitivity disc were prepared by serial doubling dilution of the extract in Dimethyl sulfoxide (DMSO). The paper discs were placed in the solution such that each disc took up $0.01 \mathrm{~m}$ to make the disc potency of $30,60,120,240$ and $480 \mu \mathrm{g}$.

\section{Test isolates}

The test isolates were confirmed enterobacteriaceae isolates obtained from prevalence study at Lamco Diagnostic Laboratory in 2009.

\section{Inoculum Standardization}

Few colonies of confirmed extended spectrum $\beta$ lactamase producers were dispensed in sterile normal saline to match the 0.5 McFarland standard for sensitivity tests as described by NCCLS (1999).

\section{Bioassay}

This was achieved by disc diffusion method (NCCLS, 1999). Standardized inocula of the confirmed ESBL producing isolates were swabbed onto the surface of prepared and solidified Mueller Hinton Agar in separate Petri-dishes.

This was followed by placing the prepared discs of the extracts and standard antibiotic discs onto the surface of inoculated media at intervals. The plates were incubated at $37^{\circ} \mathrm{C}$ for 24 hours before observation for and measurement of zones of inhibition formed.

\section{RESULTS AND DISCUSSION}

Psidium guajava plant used in this research yielded extracts amounting to $5.45 \%$ and $12.0 \%$ when subjected to extraction using ethanol and methanol as solvents respectively with the extracts having gummy texture and brown appearance as shown in Table 1. The results of phytochemical screening of the two extracts revealed the presence of alkaloids, reducing sugars, saponins, steroids and tannins. These metabolites have been reported to possess antimicrobial activity (Cowan, 1999) particularly alkaloids and tannins are well documented for antimicrobial activity (Tschehe, 1971). 
In general, the sensitivity test results showed that both Psidium guajava extracts were active against the test isolates when compared with the sensitivity of the isolates to standard ceftazidime disc with ethanol extract being active on both $K$. pneumoniae and Proteus vulgaris and methanol extract against Proteus vulgaris only at equal disc concentration of $30 \mu \mathrm{g}$ (Table 3). The antibacterial activity exhibited by both extracts may be associated with the presence of alkaloids and tannins in addition to flavonoids which was reported to be responsible for antimicrobial properties of some ethnomedicinal plants (Singh and Bhat, 2003). The mechanism of activity of flavonoids include their ability to complex with extracellular and soluble proteins and to complex with bacterial cellwalls as well as the ability of lipophilic flavonoids to disrupt microbial membranes (Tsuciya et al, 1996), that of alkaloids is attributed to their ability to intercalate with bacterial DNA (Phillipson and O'Neill, 1987) while that of tannins may be related to their ability to inactivate microbial adhesions, enzymes, cell envelope transport proteins and the ability to complex with polysaccharides (Ya et al, 1988).

Ethanol extract was more active than methanol extract with $E$. coli being insensitive to both extracts at $30 \mu \mathrm{g} /$ disc concentration. The variation in the sensitivity of different isolates tested to both extracts may be as a result of the differences in the type of ESBLs harboured by these organisms since there were more than 200 different phenotypes identified worldwide (Jacoby and Muno-Price, 2005) and different ESBLs vary in their resistance to different antibiotic substances (Paterson and Bonomo, 2005).

Table 1: Physical properties of P. guajava extracts

\begin{tabular}{lcc}
\hline \multicolumn{1}{c}{ Physical parameters } & Ethanol & Methanol \\
\hline Weight extracted $(\mathrm{g})$ & 55 & 55 \\
Weight of extract $(\mathrm{g})$ & 3.0 & 6.6 \\
Percentage yield $(\%)$ & 5.45 & 12.0 \\
Colour & Brown & Brown \\
Texture & Gummy & Gummy \\
\hline
\end{tabular}

Table 2: Phytochemical properties of $\boldsymbol{P}$. guajava extracts

\begin{tabular}{lllllll}
\hline Extracts & \multicolumn{7}{c}{ Phytochemical Tests } \\
\cline { 2 - 7 } & Alkaloids & Flavonoids & Reducing sugars & Saponins & Steroids & Tannins \\
\hline Ethanol & + & - & + & + & + & + \\
Methanol & + & - & + & + & + \\
\hline
\end{tabular}

Key: + - Present, - - Absent

Table 3: Sensitivity of ESBLs Producers to Psidium guajava extracts

\begin{tabular}{|c|c|c|c|c|c|c|c|c|c|c|c|}
\hline \multirow{4}{*}{ Isolates } & \multicolumn{4}{|c|}{ EE } & & \multicolumn{5}{|c|}{ ME } & \multirow[t]{2}{*}{ CAZ } \\
\hline & \multicolumn{10}{|c|}{ Concentration $(\mu \mathrm{g} / \mathrm{ml})$} & \\
\hline & 30 & 60 & 120 & 240 & 480 & 30 & 60 & 120 & 240 & 480 & 30 \\
\hline & \multicolumn{11}{|c|}{ Inhibition Zones ( $\mathrm{mm})$} \\
\hline Escherichia coli & 6 & 7 & 7 & 8 & 8 & 6 & 7 & 8 & 11 & 11 & 6 \\
\hline Klebsiella pnemoniae & 7 & 8 & 8 & 8 & 8 & 6 & 7 & 8 & 8 & 8 & 6 \\
\hline Proteus vulgaris & 8 & 8 & 8 & 9 & 9 & 8 & 8 & 8 & 9 & 10 & 6 \\
\hline
\end{tabular}

Key: EE - Ethanol Extracts, ME - Methanol Extracts, CAZ - Ceftazidime disc

\section{Conclusion}

From the results obtained in this work, it can be concluded that Psidium guajava has the potential for the production of drug for the treatment of urinary tract infections caused by antibiotic resistant pathogens.

\section{REFERENCES}

Aliyu, B. S. (2006): Some ethnomedicinal plants of the Savannah Regions of West Africa Description and phytochemicals. Triumph publishing company. Vol. 1: 135-152.

Asensio, A., Oliver, A.. Gonzalez-Diego, P., Baquero, F., Perez-Diaz, J. C., Ros, P., Cobo, J., Palacios, M., Lasheras, D. and Canton, R.

\section{Recommendations}

In view of the results obtained in this work, it is recommended that researchers should;

(a) Isolate and identify the active compound(s) present in the ethanol extract and fractions.

(b) Determine the toxicity level of both crude extract and the active compound(s).

(c) Screen more plants with the view of finding alternative treatments to microbial infections.

(2000): Outbreak of multiresistant $K$. pneumoniae strain in intensive care unit: an antibiotic use as risk factor for colonization and infection. Clin. Inf. Dis. 30:55-60.

Basile, A., Giordano, S., Lopez-saez, J. A. and Cobianchi, R. C. (1999): Antibacterial activity of pure flavonoids isolated from mosses. Phytochemistry. 52:1479-1482. 
Brain, K.R. and Turner, T.D. (1975): The practical evaluation of phytochemicals. Wright Scientechina, Bristol: $57-58$.

Ciulci, I. (1994): Methodology for the analysis of vegetable drugs. Chemical industries branch, Division of industrial operations. UNIDO, Romania: 24, 26 and 67.

Cosgrove, S. E., Kaye, K. S., Eliopoulous, G. M. and Carmelli, Y. (2002): Health and Economic outcomes of the emergence of third generation cephalosporin resistance in Enterobacter species. Arch. Intern. Med. 162: $185-190$.

Cowan, M. M. (1999): Plant products as antimicrobial agents. Clinical microbiology review 12(4): 564-582.

D’Agata, E., Venkataraman, L., DeGirolami, P., Weigel, L., Samore, M. and Tenover, F. (1998): The molecular and clinical epidemiology of Enterobacteriaceae producing extended spectrum $\beta$-lactamase in tertiary care hospital. J. Infect. 36: 279-285.

Fatope, A. O., Ibrahim, H. and Takeda, Y. (1993): Screening of higher plants reputed as pesticides using brine shrimp lethality bioassay. International Journal of Pharmacognosy 31: 250-256.

Jacoby, G.A. and Muno-Price, L. S. (2005): The new beta-lactamases. New Engl. Journ. Med. 352: $380-391$

Jaiary, P., Khoottaswan, P., Wongkrajang, Y., Pevngvicha, P. and Ruangsomboon (1999): Anticough and antimicrobial activity of $P$. guajava. Journal of ethnopharmacology 67(2): 203-212.

Kotra, L. P., Samama, J. and Mobashery, S. (2002): $\beta$ lactamases and resistance to $\beta$ - lactam antibiotics. In Lewis, K., Salyers, A. A., Tabar, H. W. and Wax, R. G. Eds. Bacterial resistance to antimicrobials. Marcel Decker, New York. 123-60.

Lautenbach, E., Patel, J. B., Bilker, W. B., Edelstein, P. H. and Fishman, N. O. (2001): Extended spectrum $\beta$-lactamase producing $E$. coli and K. pneumoniae: risk factors for infection and impact of resistance on outcomes. Clin. Infect. Dis. 32: 1162-1171.

Lin, R., Chin, Y. and Lee, M. (2005): Antimicrobial activity of Antibiotics in combination with
Natural flavonoids against clinical extended spectrum betalactamase-producing Klebsiella pneumoniae. Phytotherapy Research 19: 612-617.

Mukhtar, M. D. and Tukur, A. (1999): In-vitro screening for activity of Pistia stratiotes extracts. NISEB Journa/ 1(1):51 - 60 .

NCCLS (1999): Performance standard for antimicrobial susceptibility testing. National Committee for Clinical Laboratory approved standard M10059.

Oke, O. A. (2000): Phytotherapy in pregnancy; In crosscutting issue in Ethics, Law and Medicine. O. F. Emiric: Africa center of Law and human concern: 49-50.

Paterson, D. L. and Bonomo, R. A. (2005): Extended spectrum $\beta$-lactamases: Clinical update. Clin. Microbiol. Rev. 18(4): 657-686.

Phillipson, J. D. and O'Neill, M. J. (1987): New leads to the treatment of protozoal infections based on natural product molecules. Acta Pharm. Nord. 1: 131-144

Singh B. and Bhat T. K. (2003): Potential therapeutic applications of some antinutritional plant secondary metabolites. Journ. Agric. Food Chem. 51:5579-5597.

Sofowora, A. (1993): Medicinal plants and Traditional Medicines in Africa. Chichester John Wiley \& Sons New York. Pp. 34-36.

Tschehe, R. (1971): Advances in the chemistry of antibiotic substances from higher plants: Pharmacognosy and phytochemistry. In proceeding of $1^{\text {st }}$ International Congress, Munich, 1970: 274-289.

Tsuciya, H., Sato, M., Miyazaki, T., Fujiwara, S., Tanigaki, S., Ohyama, M., Tanaka, T. and Iinuma, M. (1996): Comparative study on the antibacterial activity of phytochemical flavones against methicillin-resistant Staphylococcus aureus. Journ. Ethnopharmacol. 50: 27-34.

Ya, C., Gaffney, S. H., Lilley, T. H. and Haslam, E. (1988): Carbohydrate polyphenol complexation, In R. W. Hemingway and J. J. Karchesy (ed.), Chemistry and significance of condensed tannins. Plenum press New York. P553. 